University of Nebraska - Lincoln

DigitalCommons@University of Nebraska - Lincoln

$11-1-2004$

\title{
The differential relations of maternal and paternal support and control to adolescent social competence, self-worth, and sympathy
}

\author{
Deborah J. Laible \\ Southern Methodist University, del205@lehigh.edu \\ Gustavo Carlo \\ University of Nebraska-Lincoln, carlog@missouri.edu
}

Follow this and additional works at: https://digitalcommons.unl.edu/psychfacpub

Part of the Psychiatry and Psychology Commons

Laible, Deborah J. and Carlo, Gustavo, "The differential relations of maternal and paternal support and control to adolescent social competence, self-worth, and sympathy" (2004). Faculty Publications, Department of Psychology. 30.

https://digitalcommons.unl.edu/psychfacpub/30

This Article is brought to you for free and open access by the Psychology, Department of at DigitalCommons@University of Nebraska - Lincoln. It has been accepted for inclusion in Faculty Publications, Department of Psychology by an authorized administrator of DigitalCommons@University of Nebraska - Lincoln. 


\title{
The Differential Relations of Maternal and Paternal Support and Control to Adolescent Social Competence, Self-Worth, and Sympathy
}

\author{
Deborah J. Laible \\ Southern Methodist University \\ Gustavo Carlo \\ University of Nebraska, Lincoln
}

The goal of this study was to examine how the parenting dimensions of both mothers and fathers independently and together predict adolescent outcomes in three domains: sympathy, self-worth, and social competence. One-hundred eight adolescents completed self report measures on their perceived relationship with parents, sympathy, social competence, and self-worth. Perceived maternal support and rigid control were the most consistent predictors of adolescent adjustment. High levels of perceived maternal support and low levels of maternal rigid control were related to adolescents' reports of sympathy, social competence, and self-worth. In contrast, support and control from fathers was generally unrelated to adolescent adjustment. The one exception was in predicting sympathy, where father support interacted with maternal support in predicting sympathy. When perceived support from fathers was high, maternal support was unrelated to sympathy. In contrast, when perceived support from fathers was low, perceived maternal support was a statistically significant predictor of sympathy.

Keywords: parenting; sympathy; self-worth; social competence; support; control

Over the past three decades, research has extensively examined the impact of parenting styles on child outcomes. The vast majority of research with young children has supported the idea that children raised by authoritative parents (i.e., those high on both responsiveness and demandingness) are the most competent (see Maccoby \& Martin, 1983, for a review). More recent

Please address correspondence to Deborah Laible, Department of Psychology, Southern Methodist University, Dallas, TX 75275-0442; e-mail: dlaible@mail.smu.edu. The authors would like to thank Billy Aplin for his help with this project. In addition, the authors would like to thank April Scheuths for her help on this project and the parents, teachers, faculty, staff, and students from Lincoln Northeast High School for their help with the project. Support for this project was provided by a National Institutes of Health Predoctoral National Research Service Award to the first author and by a Layman Foundation Award to the second author.

Published in Journal of Adolescent Research, Vol. 19 No. 6, November 2004 759-782

Copyright (C) 2004 Sage Publications. Used by permission. 
research examining the relations between parenting styles and adolescent outcomes have largely paralleled the findings of research with younger children. This research has supported the importance of warm and demanding parents in determining adolescent adjustment in multiple domains, including school success, substance abuse, and psychosocial adjustment (Baumrind, 1991; Dornbusch, Ritter, Leiderman, Roberts, \& Fraliegh, 1987; Grolnick, Ryan, \& Deci, 1991; Lamborn, Mounts, Steinberg, \& Dornbusch, 1991; Steinberg, Elmen,\&Mounts, 1989). Thus, in general, research has suggested that the best outcomes for adolescents and children are associated with authoritative parenting, although there is some evidence that this influence may vary by ethnic and cultural groups and by the child's socioeconomic status (SES) (e.g., Lamborn, Dornbusch, Sanford, \& Steinberg, 1996).

Research on support and control, the two dimensions presumed to define parenting styles, supports that both individually predict adolescent adjustment. Support and warmth from parents continue to play an important role in fostering healthy socioemotional development across adolescence, even when the support of peers becomes increasingly important (Laible, Carlo, \& Raffaelli, 2000; Maccoby \& Martin, 1983). Support and warmth from parents are presumed to enhance social, emotional, and moral competence through several mechanisms. First, children are more likely to embrace parental values if they perceive their relationships with parents as mutually responsive (Kochanska \& Thompson, 1997). Second, children are also presumed to acquire through positive relationships with parents positive affective social orientations that generalize to others (Putallaz \& Heflin, 1990). Finally, children are also thought to gain important social information processing skills from parental interactions, information that, in turn, enhances interactions with peers (Pettit, Harris, \& Bates, \& Dodge, 1991). Thus, unsurprisingly, research from both the attachment literature and support literatures has linked parental support and warmth with a variety of positive socioemotional outcomes in adolescence, including high levels of self esteem and pro social behavior and low levels of aggression, anxiety, and depression (Armsden \& Greenberg, 1987; Barnes \& Olson, 1985; Laible et. al. , 2000; Maccoby \& Martin, 1983; Papini \& Roggman, 1992).

In contrast to support, the influence of parental control on adolescent adjustment is less clear-cut and seems to depend on the type of control. Whereas flexible, behavioral control has been linked with a variety of positive adolescent outcomes (Maccoby \& Martin, 1983; Patterson, Bank, \& Stoolmiller, 1990), rigid or psychological control by parents seems to be detrimental to healthy adolescent adjustment. Parental control that involves too much intrusiveness and parental direction or control through guilt has been linked with both adolescent externalizing problems and internalizing problems (Barber, 1996; Barber, Olsen, \& Shagle, 1994). Rigid control is believed to have its negative impact on adolescent psychosocial development not only because it impairs and exploits the parent-child bond but also because it is often accompanied by negative affect and because it takes away from an adolescent's sense of personal control (Barber, 1996). Similar to rigid control, parenting practices that are harsh, coercive, or that involve rejection have been consistently linked with poor adolescent outcomes, including antisocial behavior and delinquency (Dornbusch et al., 1987; Maccoby \& Martin, 1983; Patterson, 1986). In particular, rejection by parents appears to be especially detrimental to the internalization of parental values and to the development of moral emotions such as sympathy. The negative emotions that such harsh parenting practices arouse are likely to be too high to be effective in socialization (Hoffman, 1983).

Despite the relative abundance of research on parenting dimensions (such as support or rigid control), the separate and unique influences of maternal and paternal parenting dimensions on adolescent socialization remains virtually unexplored (for an exception, see Shek, 1998). The majority of studies on parenting ask adolescents to rate either their relationship with their mother or with their parents as a single entity-and not separately (e.g., Armsden \& Greenberg, 1987; Garber, Robinson, \& Valentiner, 1997; Hein \& Lewko, 1994; Mantzieopoulos \& Oh-Hwang, 1998; Taris $\&$ Semin, 1998). Other researchers have asked adolescents to rate their relationships with mothers and fathers separately. However, in these studies, researchers have tended to either average or aggregate the parenting styles of both parents to provide a single overall index of parenting styles (Lamborn et. al., 1991; Steinberg, Lamborn, Dornbusch, \& Darling, 1992). Researchers have typically adopted this approach because the relationship between maternal and paternal parenting styles has generally been high, suggesting that mothers and fathers within the same household have relatively similar parenting styles.

However, research on parent-child relationships in adolescence suggests that mothers and fathers have unique and different relationships with children and adolescents (Larson \& Richards, 1994), and as a result, combining their influence in predicting adolescent outcomes may be unwise. For example, mothers typically spend more time with adolescents, are involved in a broader range of activities with them, and are more likely to provide care giving than fathers. Fathers, in contrast, tend to spend much of their time with children and adolescents involved in leisure time and instrumental activities (Holmbeck, Paikoff, \& Brooks-Gunn, 1998; Youniss \& Smollar, 1985). In addition, mother-child relationships may undergo more of a 
transformation than father-child relationships during the transition to adolescence (Collins \& Russell, 1991) in that mothers are more likely to experience an increase in conflictual interactions with adolescents during this period. Despite this, however, mother-child relationships in adolescence tend to involve more mutuality, closeness, and support than father-child relationships (Collins \& Russell, 1991).

It seems likely that because mothers and fathers have different relationships with adolescents, support and rigid control from mothers and fathers might impact different domains of development. The small amount of research that has examined the relative influence of maternal and paternal parenting dimensions on adolescent outcomes supports the idea that maternal and paternal parenting styles impact different domains of adolescent adjustment. Fischer and Crawford (1992), for example, found that the parenting style of fathers, and not mothers, was related to the codependency scores (i.e., a focus outside the self) of both sons and daughters. Feldman and Wentzel (1990) also found differences in the ability of maternal and paternal parenting dimensions to predict adolescent outcomes. In their study, social impact by adolescents was predicted solely by power-assertive discipline by fathers and not mothers. Feldman and Wentzel, however, also found that both maternal and paternal support and child-centered practices similarly predicted popularity.

The question of how maternal and paternal parenting dimensions uniquely impact adolescent adjustment may be complicated by several factors. First, the influence of parental support and control may vary based on the gender of the child and of parent. Researchers have suggested that children may be more likely to identify with, and therefore model the behavior of, the same-sex parent (e.g., Zakharov, 1982). Thus, for example, it may be that paternal support is more important for adolescent males in fostering adjustment in particular domains (e.g., aggression), and support from mothers may be more important for daughters in other domains (e.g., self-esteem). Second, the influence of the support or control from one parent may vary depending on the support or control from the other parent. For example, support from one parent may be especially important when support of the other parent is lacking. Unfortunately, all of these issues remain, for the most part, empirically unexplored.

\section{The Current Study}

The goal of the current study was to examine how adolescents' perceptions of support and rigid control from both mothers and fathers independently and together predicted adolescent outcomes in three domains: sympathy, self-worth, and social competence. These outcome measures were selected because they are considered markers of positive youth development. Much of the work on parenting in the recent past has focused on the development of problematic adolescent adjustment, such as drug use or depression, and has not emphasized how parenting dimensions might foster the development of adolescent strengths. Thus, we wished to expand on the fairly recent literature on healthy youth adjustment.

In addition, researchers have speculated about the importance of parental support and the lack of rigid control for the development of these three competencies. Support and warmth from parents are considered particularly important in fostering sympathy, or a child's ability to understand and respond emotionally to another distress; social competence, or success with peers; and self-worth. In particular, the affective climate of the home is presumed to be an important factor in the socialization of sympathy and social competence, as well as an import arena in which to develop self-worth (Garber et al., 1997; Zahn-Waxler \& Radke-Yarrow, 1990). Warm, supportive relationships with parents are thought to foster secure parent-child attachments, which, in turn, are related to a child's level of empathy, social competence, and feelings of self-worth (Laible et al., 2000).

Rejecting or controlling parent-child relationships, in contrast, characterized by frequent negative affect, are presumed to contribute to a heightened sense of distress that will inhibit the development of sympathy and other moral emotions (Eisenberg et al., 1992; Zahn-Waxler \& Radke-Yarrow, 1990). Likewise, excessive control by parents is not responsive to adolescents' psychological or emotional needs and stifles their development of autonomy, which discourages interaction with others and the development of social competence (Barber, 1996). Finally, rigid control or control coupled with rejection from parents detracts from an adolescent's sense of control over the environment and contributes to feelings of unworthiness (Kerr \& Stattin, 2000).

Thus, our study examined two dimensions of perceived parenting (i.e., support and rigid control) that have been theoretically and empirically linked to the development of sympathy, social competence and self-worth in adolescence. Parenting dimensions were selected because they were more specific than parenting styles per se, and as a result, it is often difficult to decipher those aspects of a parenting style (e.g., support, control, or communication) that produce certain outcomes (Lewis, 1981). Previous research has supported the idea that support, particularly from parents in adolescence, is a multidimensional construct involving not only warmth and affection but also acceptance, involvement, and understanding (Barber \& Thomas, 1986; Ferreira \& Thomas, 1984). We adopted this approach as well, including not only involvement, acceptance, and understanding by 
parents but also two other dimensions that are important for adolescents: cognitive independence and egalitarianism. Cognitive independence and egalitarianism are both measures of the parents' willingness to allow adolescents to think independently. Although these dimensions have not typically been considered part of parental support, these two constructs seem to be an important aspect of support in adolescent-parent relationships. In addition, researchers have speculated that such democratic aspects of parent-child relationships likely foster an adolescent's sense of control over the environment, thus enhancing self worth and fostering democratic thinking, which, in turn, likely fosters perspective taking and social competence (Kerr \& Stattin, 2000).

Based on the previous work, it was generally expected that support from mothers and fathers would predict positive adjustment and that rigid control would be inversely related to adjustment in all three domains. The question that was not clear, however, was whether perceived paternal and maternal support and rigid control would predict similar or different domains of adolescent adjustment. In addition, researchers have not tended to analyze whether support or control from one parent interacts with that of the other in producing adolescent outcomes or whether the gender of the child is an important determinant of whether parenting dimensions predict outcomes. Because of the lack of research into these questions, no a priori hypotheses were made.

\section{METHOD}

\section{Participants}

One-hundred nine public middle and high school students participated in the study $(\mathrm{M}$ age $=16.1, \mathrm{SD}=.90 ; 56 \%$ female $)$. The adolescents were primarily Caucasian (92\%), came from predominantly two-parent households $(81 \%)$, and were recruited through one public middle school and one public high school. Parental consent forms were sent home with adolescents, and those who returned the parental consents completed the questionnaires in classrooms with the help of participating schools. Adolescent assent was also obtained from adolescents prior to their completion of questionnaires. The schools were located in a mid sized midwestern town, and the ethnic make-up of the sample was generally representative of the midwestern city.

\section{Measures and Procedures}

The surveys consisted of a number of demographic items and a battery of scales. All of the scales had been previously used with adolescents. Demographic items included two questions about the parents' levels of education (rated on a 7-point scale). Of adolescents, $40.4 \%$ reported that their fathers had a 4-year college or advanced degree, and 39.5\% reported that their mothers had a 4-year college or advanced degree. The survey also included the scales listed below.

Perceived parental support and rigid control. Both mothers' and fathers' adolescents completed the Parent Behavior Form (Worell \& Worell, 1974) to describe their relationship with each parent. The Parent Behavior Form is designed to assess the adolescents' perceptions of their relationships with parents on seven dimensions: acceptance (for mothers, $\alpha=$ .94 for mothers; for fathers, $\alpha=.92$ ); active involvement (for mothers, $\alpha=$ .93; for fathers, $\alpha=.92$ ); egalitarianism (for mothers, $\alpha=.90$; for fathers, $\alpha$ $=.89$ ); cognitive independence (for mothers, $\alpha=.89$; for fathers, $\alpha=.89$ ); cognitive understanding (for mothers, $\alpha=.89$; for fathers, $\alpha=.89$ ); strict control (for mothers, $\alpha=.80$; for fathers, $\alpha=.83$ ); and rejection (for mothers, $=.79$; for fathers, $\alpha=.74$ ). The Parent Behavior Form is a fairly widely used measure of parenting behavior and has been shown to be reliable and valid in previous research (see e.g., Haberstroh, Hayslip, \& Essandoh, 1998; Schoenrock, Bell, Sun, \& Avery, 1999). Each subscale consisted of nine items that were rated on a 5-point scale $(1=$ does not describe me very well and $5=$ describes me very well). Sample items were as follows: "comforts me when I'm afraid" (acceptance); "believes in showing his or her love for me" (active involvement); "allows discussion of right and wrong" (egalitarianism); "likes when I ask questions about all kinds of things" (cognitive independence); "feels I should read as much as possible on my own" (cognitive understanding); "wants to control whatever I do" (strict control); and "makes me feel not loved" (rejection).

To reduce the number of predictors and to create factors that reflect support and control, adolescents' scores on each of these seven subscales were submitted to a principal components factor analysis with varimax rotation. Both eigenvalues and Scree Plots were used to determine factors. We also chose a more conservative cutoff point $(>.50)$ to interpret factors (Tabachnick \& Fidell, 1996). 
TABLE 1: Principal Components Factor Analysis (with varimax rotation) of the Scales From the Parent Behavior Form

\begin{tabular}{lccllll}
\hline & \multicolumn{2}{c}{ Support } & & \multicolumn{2}{c}{ Rigid Control } \\
\cline { 2 - 3 } & Mother & Father & & & Mother & Father \\
\hline Acceptance & .84 & .86 & & -.41 & -.37 \\
Active involvement & .88 & .88 & & -.29 & -.19 \\
Egalitarianism & .81 & .84 & & -.46 & -.43 \\
Cognitive independence & .93 & .90 & & -.17 & -.22 \\
Cognitive understanding & .87 & .85 & & -.02 & -.06 \\
Strict controls & -.05 & -.06 & & .94 & .93 \\
Rejection & -.55 & -.60 & & .68 & .60 \\
\hline
\end{tabular}

NOTE: Loadings greater than . 50 were used for interpretation.

Two distinct and parallel factors emerged for both mothers and fathers, and these factors were retained for subsequent analyses. Factor loadings for both mothers and fathers can be seen in Table 1 . The first factor for both mothers (eigenvalue $=4.9 ; 69.2 \%$ of the variance) and fathers (eigenvalue $=4.8 ; 67.5 \%$ of the variance) was labeled support and was composed of acceptance, active involvement, egalitarianism, cognitive understanding, and cognitive independence. Rejection also loaded negatively on both of these support factors. The second factor for both mothers (eigenvalue $=1.1$; $15.1 \%$ of the variance) and fathers (eigenvalue $=0.91,14.0 \%$ of the variance) 1 was labeled rigid control and consisted of rejection and strict controls. Item analysis of the strict control scale (e.g., "wants to control whatever I do" and "tells me how to spend my free time") suggested that this scale was more akin to rigid control rather than flexible behavioral control and in fact has items similar to measures of rigid control and/or psychological control (e.g., Barber, 1996). The fact that rejection also loaded on this scale supported this notion.

Sympathy. Students completed the empathic concern and perspective taking subscales from the Interpersonal Reactivity Questionnaire (Davis, 1983). Both the empathic concern scale ( $\alpha=.73$ in the present study) (sample item: "I often have tender, concerned feelings for people less fortunate than me") and the perspective-taking scale (in the present study, $\alpha=.71$; sample item: "I sometimes find it difficult to see things from the 'other person's' point of view") consisted of seven items. Both scales were rated on a 5 -point scale ranging from $1=$ does not describe me to $5=$ describes me very well.

Because perspective taking and empathic concern are theoretically and empirically related (Davis, 1983), a sympathy scale was formed by combin- ing the two scales. Preliminary correlational analysis indicated that the empathic concern and perspective-taking subscales were significantly interrelated $(\mathrm{r}(89)=.46, \mathrm{p}<.001)$. Following previous researchers (e.g., Carlo, Roesch, \& Melby, 1998; Laible et al., 2000), the two scales were summed and averaged to form the sympathy scale ( $\alpha=.72$ in the present study). Social competence and self-worth. Adolescents also completed two scales from Harter's (1982) Perceived Competence Scale designed to measure perceived social competence and self-worth. Prior research has found this measure to have adequate reliability and validity use with adolescents (e.g., Cauce, 1987; Granleese \& Joseph, 1993). Social competence had 5 items $(\alpha=.63)$, and self-worth consisted of 10 items $(\alpha=.66)$. For both scales, adolescents are asked to pick between two statements and then to indicate whether the chosen item was either "really true" or "sort of true" of them (sample item for social competence: "Some teenagers find it hard to make friends, but for others it's pretty easy"; sample item for self-worth: "Some teenagers are often disappointed with themselves, but other teenagers are pleased with themselves.") Social desirability. As a statistical control, a shortened version of Crown and Marlowe's (1960) Social Desirability Scale was also administered. Adolescents were asked to indicate if each of the 10 statements were true or false (in the present study, $\alpha=.60$; sample item: "I have never intensely disliked anyone").

\section{RESULTS}

\section{Descriptive Data and Bivariate Relations}

To examine whether mothers or fathers were rated as higher on dimensions of support and rigid control, $t$ tests were conducted. Mothers were rated significantly higher than fathers by adolescents on levels of acceptance $(\mathrm{t}=2.20, \mathrm{p}<.05)$, active involvement $(\mathrm{t}=3.81, \mathrm{p}<.01)$, and rigid control $(\mathrm{t}=1.97, \mathrm{p}=.05)$.

Bivariate correlations for perceived maternal and parental support and rigid control and social competence, self-worth, and sympathy appear in Table 2.A conventional level of $\mathrm{p}<.05$ was used to determine significance of all subsequent relations. Consistent with previous research, perceptions of maternal and paternal support were related, as were perceptions of maternal and paternal rigid control. Adolescents who reported high levels of support from mothers also tended to report high levels of support from fathers. Similarly, 
TABLE 2: Bivariate Correlations Among Paternal and Maternal Support and Control and Adolescent Positive Adjustment Factors

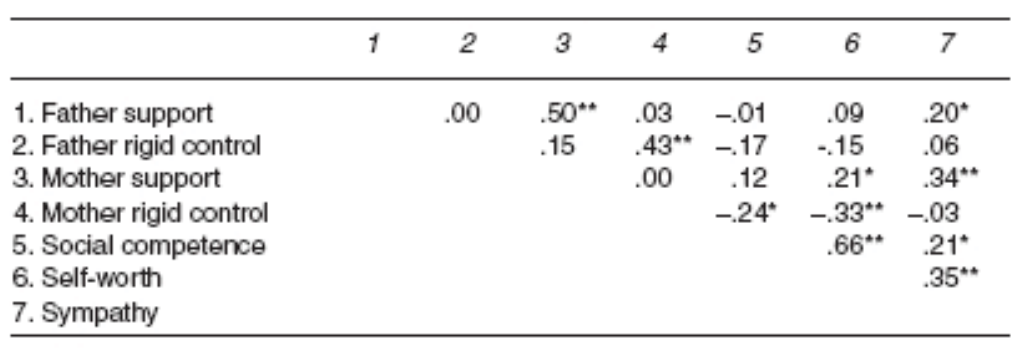

NOTE: $N=99$ for correlations with paternal variables; $N=109$ for correlations with matemal variables.

${ }^{*} p<.05 .{ }^{*} p<.01$ (both values two-tailed).

adolescents who perceived high levels of rigid control from fathers also perceived high levels of rigid control from mothers. Paternal support was correlated only with sympathy; adolescents who reported high levels of paternal support reported higher sympathy. In contrast, perceived maternal support was related to self-worth and sympathy. Adolescents who reported high levels of support from mothers also reported having high levels of self worth and sympathy. Although rigid control from fathers was unrelated to any of the adolescent adjustment variables, rigid control from mothers was negatively related to perceived social competence and self-worth. Thus, adolescents who reported high levels of rigid control from mothers also reported lower levels of perceived social competence and self-worth.

\section{Regression Models Predicting Social \\ Competence, Self-Worth, and Sympathy}

To understand the differential relations between perceived maternal and paternal parenting and the adolescent positive adjustment indices, a series of hierarchical regression models was built (see Tables 3, 4, and 5). Separate regression models were built using maternal and paternal variables because of the substantial overlap between the maternal and paternal parenting dimensions. Including both maternal and paternal support in a single regression model typically produced enough collinearity among the predictors to wash out the effects of all predictors. Tolerance levels among maternal and paternal parenting variables were less than .72 if the parenting dimensions of both parents were included in a single regression model. In addition, keeping the maternal and paternal parenting dimensions in separate models allowed for the comparison of the pat-

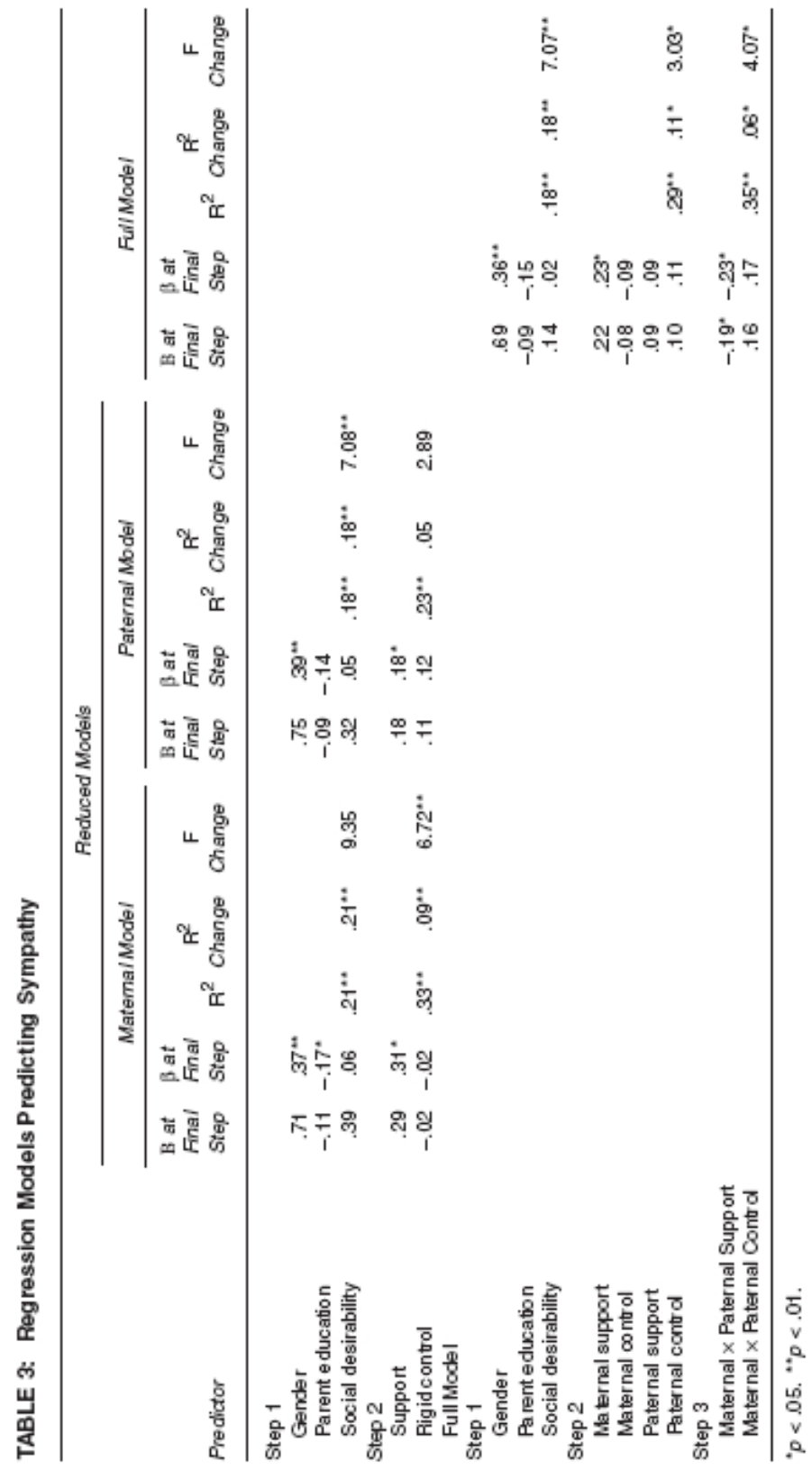



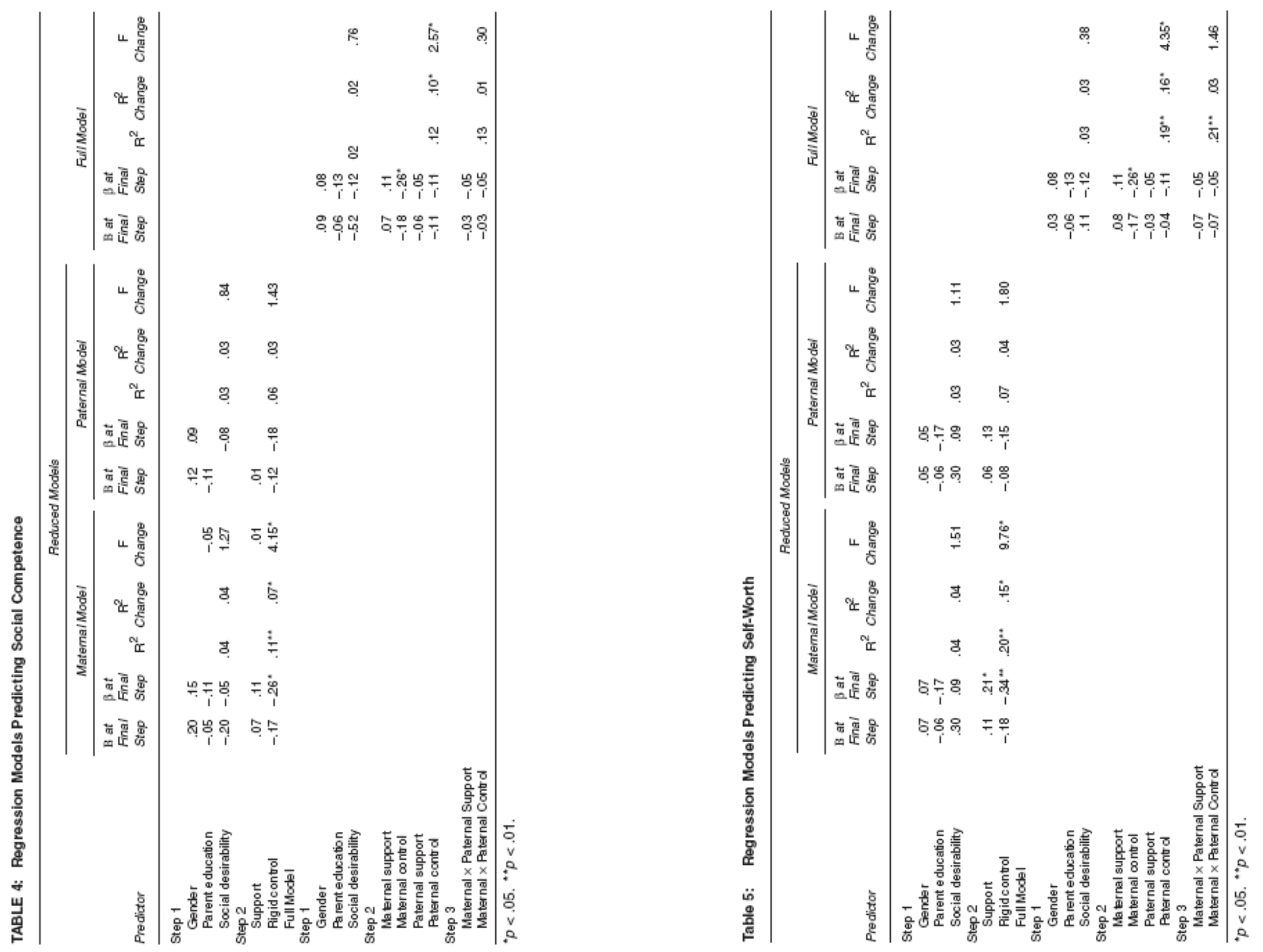
tern of relations of each parent in predicting outcomes.

Gender, parent education (as an index of SES), and social desirability were entered on the first step to statistically control for their effects. Previous research has found relations among the criterion variables (e.g., sympathy) and gender and SES (Dekovic \& Janssens, 1992; Eisenberg \& Lennon, 1983). Social desirability was also included as a control to reduce some of the bias variance inherent in the nature of self-report data. The variables of interest, perceptions of maternal or paternal support and control, were entered on the second and final step of the regression models predicting social competence, self-worth, and sympathy.

To examine whether the relative influence of support or control from one parent depended on the level of support and control from the other parent, a third full regression model was generated that included the interaction terms between both of the maternal and paternal variables (i.e., maternal support by paternal support and maternal rigid control by paternal rigid control). Thus, in the full model, social desirability, gender, and parent education were entered on the first step, maternal and paternal support and rigid control were entered on the second step, and the interaction terms were entered on the final step.

In the two reduced models predicting sympathy, the addition of gender, social desirability, and parent education on the first step of both models accounted for a statistically significant amount of systematic variance in sympathy. For the model using maternal parenting variables, the addition of maternal support and rigid control increased significantly the amount of variance accounted for in sympathy and led to a statistically significant overall predictive model. Gender, maternal support, and parent education made statistically significant independent contributions to the final predictive model. Girls, those with less educated parents, and those who reported high levels of maternal support had the highest levels of sympathy. For the second model using paternal parenting variables, the addition of paternal support and control only increased the amount of variance accounted for in sympathy at a borderline statistically significant level. The final reduced model, however, was statistically significant, and both gender and paternal support made statistically significant, independent contributions to the model. Similar to the model using maternal predictors, girls and adolescents reporting high levels of paternal support also reported high levels of sympathy.

In the full model predicting sympathy, the addition of the control variables on the first step, the parenting variables on the second step, and the interaction terms on the third step increased significantly the amount of variance accounted for in the model and led to a statistically significant overall

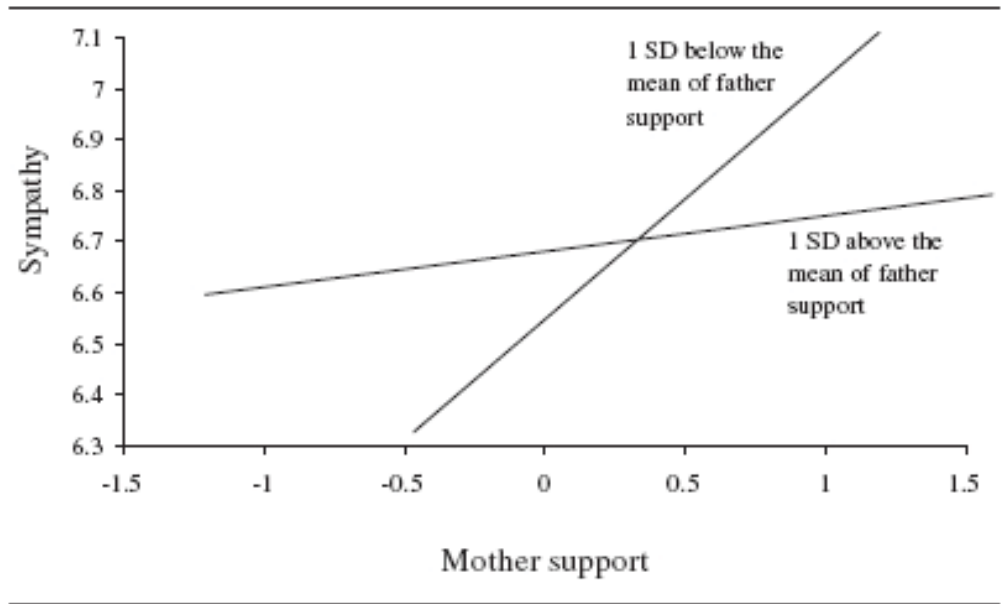

Figure 1. Interaction between maternal support and paternal support in predicting sympathy in adolescents.

predictive model. In this model, maternal support, gender, and the interaction term between maternal and paternal support all made statistically significant, independent contributions to the model. Girls and those with high perceived support from mothers reported the highest levels of sympathy.

To examine the interaction, the relation between maternal support and sympathy was graphed at 1 standard deviation above and 1 standard deviation below the mean of father support (following Aiken \&West, 1991), and this graph appears in Figure 1. Maternal support was related to increases in sympathy for both levels of father support (i.e., the slopes of both lines are positive). Significant increases in sympathy were associated with maternal support when support from fathers was low (i.e., 1 standard deviation below the mean; $\alpha=.47, \mathrm{t}=3.48, \mathrm{p}<.01)$. When support from fathers was high, however, support from mothers was also linked with increases in sympathy (i.e., the slope of the line is positive but not statistically significant; $\alpha=.07, \mathrm{t}=.51, \mathrm{p}>.05)$.

In predicting social competence, the addition of gender, parent education, and social desirability on the first step of both reduced models did not account for a statistically significant amount of systematic variance. The addition of maternal support and control on the second step of the model using maternal predictors significantly increased the variance accounted for and led to an overall statistically significant predictive model. Only maternal control made an independent contribution to the model. Adoles- 
cents who reported high levels of maternal rigid control also reported lower levels of perceived social competence. In contrast, in the model using paternal predictors, the addition of paternal support and control on the second step did not increase significantly the amount variance accounted for by the model.

In the full model (with both maternal and paternal predictors) predicting social competence, the addition of the maternal and paternal support variables on the second step increased significantly the amount of variance. Maternal control, however, made a statistically significant, independent contribution to the full model. The higher adolescents perceived rigid control from mothers, the lower their levels of perceived social competence. The addition of the interaction terms in the third step did not account for statistically significant additional predictive variance.

In the model predicting self-worth, the addition of gender, parent education, and social desirability did not increase significantly the amount of variance accounted for by either reduced model. The addition of maternal support and rigid control in the second step increased significantly the amount of variance accounted for in the model and led to a statistically significant overall predictive model. Both maternal support and control made statistically significant, independent contributions to the model. High levels of maternal support and low levels of maternal rigid control were related to high scores on self-worth. In the model using the paternal predictors, however, the addition of paternal support and control on the second step of the model did not increase significantly the amount of variance accounted for by it.

In the full model predicting self-worth, the addition of the maternal and paternal parenting variables on the second step of the model increased significantly the amount of variance in the model and led to a statistically significant overall predictive model. Only maternal rigid control, however, made a statistically significant independent contribution to the full model. Adolescents who reported high levels of perceived control from mothers reported lower levels of self-worth. The addition of the interaction terms on the third step did not account for significant additional systematic variance.

\section{Interactions With Gender}

To determine whether the relations between maternal and paternal parenting and adolescent adjustment varied by the gender of the child, interactions between gender and maternal and paternal support and rigid control were also examined in the reduced models. None of these interactions were statistically significant, and thus, they are not reported here. Thus, the gen- der of the child did not seem to moderate the relations between parenting and social competence, self-worth, and sympathy.

\section{Interactions Between Support and Rigid Control}

Finally, interactions between support and rigid control were also examined in the reduced regression models for both fathers and mothers. None of these interactions were statistically significant either, and thus, they are not reported here.

\section{DISCUSSION}

The goal of this study was to examine the unique relations of maternal and paternal support and rigid control to sympathy, social competence, and self esteem. The pattern of results from this study suggest that the predictive value of maternal and paternal support and control not only varied depending on the outcome assessed but also varied depending on whether the influence of the other parent is taken into account. In the study, perceived support and rigid control from mothers were the most consistent predictors of adolescents' reports of sympathy, social competence, and self-worth. Perceived support from mothers was associated with both higher levels of sympathy and self-worth in adolescents. In contrast, perceived rigid control from mothers was associated with lower levels of self-worth and perceived social competence in adolescents.

It is important to note that maternal support interacted with paternal support in predicting adolescents' reports of sympathy. For adolescents who reported extremely unsupportive relationships with fathers, support from mothers was associated with high levels of sympathy. In contrast, however, for those adolescents with extremely supportive relationships with fathers, support from mothers was not associated with high levels of sympathy. These findings are interesting because they suggest that support from a mother can serve as a protective factor in the development of sympathy, buffering a child against an unsupportive relationship with a father.

In contrast to maternal parenting dimensions, perceived paternal support and rigid control was unrelated to most of the adolescent outcome measures. The only exception was for sympathy, where paternal support was just as predictive as was maternal support in predicting sympathy. Higher levels of perceived support from fathers were related to higher scores on the sympathy scale. Why paternal parenting dimensions were not as predictive as maternal parenting dimensions for adolescent outcomes is unclear. One possibility is that maternal parenting dimensions are more influential in predicting adolescent outcomes because mothers typically spend 
more time with adolescents (Larson \& Richards, 1994). In addition, adolescents typically report higher levels of intimacy and disclosure with mothers than with fathers in adolescence (Larson \& Richards, 1994; Youniss \& Smollar, 1985), and this open discourse and intimacy between mothers and adolescents may be especially important in fostering social competence and self-worth. The current study provides some support for the idea that mothers are seen as more involved and accepting than are fathers. On the parent behavior form, mothers were rated significantly higher than were fathers on acceptance, involvement, cognitive understanding, and strict control, suggesting that the adolescents saw mothers as being more involved, more understanding, and also more likely to implement strict control.

Alternatively, it may also be that paternal parenting dimensions were not predictive of adolescent outcomes because of the outcome measures selected. Perceived paternal support and control may be important for fostering adolescent adjustment in areas beyond those examined in this study (e.g., in preventing antisocial behavior). Research with younger children suggests that father involvement may be important for the development of an internal locus of control, independence, and need for achievement (Sagi, 1982; Sagi, Koren, \& Weinberg, 1987). Research with young adults suggests that a strong attachment relationship with fathers during adolescence may also be related to other domains of adolescent adjustment, including more educational attainment, less depression, and lower likelihood of being imprisoned (Furstenberg \& Harris, 1983).

The current study did not find that the gender of the child influenced the impact of either perceived maternal or paternal support and rigid control. This is interesting in light of the evidence that adolescent relationships with fathers and mothers may vary depending on the gender of the adolescent (see Larson \& Richards, 1994; Youniss \& Smollar, 1985). Researchers have found, for example, that father-daughter relationships are the most difficult and distant of the relationships during this period. Father-son relationships, though closer and friendlier than father-daughter relationships in adolescence, are still characterized by emotional distance (with sons feeling less accepted and less strong in the presence of fathers). Mother-daughter relationships have been characterized by a mixture of authority and equality, closeness and conflict. Mother-son relationships have been characterized as generally loving, instrumental, and honest. Given these differences, it was somewhat surprising that gender did not influence the effect of perceived parental support or control on adolescent outcomes.

It is important to note that although our findings suggested that rigid or excessive control, although from mostly mothers, was associated with poor adolescent adjustment, flexible control has been associated with positive youth adjustment (Maccoby \& Martin, 1983; Patterson et al., 1990). For example, research with permissive parents (i.e., those low on demandingness and high on responsiveness) finds links between lack of parental control and substance abuse, school failure, and antisocial behavior (Carlo et al., 1998; Patterson, 1986; Patterson et. al, 1990; Steinberg, 1990). Similarly, research on parental monitoring suggests that parents who monitor adolescents have children who do better in school, who are less delinquent and aggressive, and who engage in less risky behavior (Carlo, Raffaelli, Laible, \& Myers, 1999; Crouter, MacDermid, McHale, \& Perry-Jenkins, 1990; McCord, 1986; Metzler, Noell, Biglan, Ary, \& Smolkowski, 1994; Sampson \& Laub, 1990). Parental control and supervision is presumed to enhance adolescent outcomes by ensuring appropriate parental reactions to prosocial and antisocial activities and by limiting adolescent's contact with delinquent peers (Snyder \& Patterson, 1987).

Overall, the relations between perceptions of maternal and paternal support and rigid control and adolescent adjustment in this study were modest. This is consistent with much of the parenting literature with adolescents and it may be, as others have argued, that specific parenting practices (i.e., parenting behaviors), rather than global parenting dimensions, are more predictive of adolescent outcomes (Darling \& Steinberg, 1993). In prior research, relations between parental support and adolescent outcomes have often been mixed and sometimes nonsignificant (Darling and Steinberg, 1993; Eisenberg \& Murphy, 1995). Darling and Steinberg (1993) suggest that support reflects affective climate and that it sometimes has indirect rather than direct effects on adolescent outcomes and that there is empirical support for this hypothesis (Carlo et al., 1998). Clearly, future research that systematically examines both direct and indirect effects of parental support on adolescent outcomes is needed.

Furthermore, the modest relations found in this study might also be because support of peers, rather than that of parents, may be relatively more influential in promoting positive adolescent adjustment during adolescence (Laible et al., 2000). Furthermore, it is important to note that because of the correlational nature of the study, it is not possible to confidently determine the direction of the observed effects. Although it seems plausible that parental support and lack of rigid control foster adolescent well-being, a reasonable argument can be made that the direction of the effects is reversed (i.e., well-adjusted adolescents evoke different responses from parents than poorly adjusted ones). As Bell (1968) and others (Maccoby \&Martin, 1983) have argued, however, the effects are likely bidirectional in nature. Final- 
ly, of course, our data are limited because of their self-report nature and because of the sample size and homogeneity.

In conclusion, this study provides evidence that maternal and paternal support and rigid control may serve both similar and different functions in promoting or undermining adolescent adjustment. Thus, the challenge for researchers is to explore the ways that maternal and paternal parenting dimensions work separately and together in promoting adolescent adjustment. Because of this, it is crucial that researchers consider separately the influences of maternal and paternal parenting dimensions on adolescent outcomes. Summing or averaging scores on maternal and paternal parenting styles (even when they are highly correlated) can obscure the different pattern of relations between the parenting dimensions and outcome assessments.

Finally, future researchers might also want to examine how the congruence between maternal and paternal parenting styles impacts adolescent adjustment. There is, in fact, some interesting research (Johnson, Shulman, \&Collins, 1991) that suggests that the congruence of parenting patterns may have implications for a child's psychosocial outcomes. These researchers found that adolescents who perceived their parents as having incongruent parenting patterns were more likely to have lower levels of self-esteem and academic achievement than were those who perceived congruent parenting patterns. Clearly, this is an important finding and deserves further attention by researchers.

\section{NOTES}

1. Even though the eigenvalue was less than the traditional 1.0 cutoff, this factor was retained for theoretical reasons because of the Scree Plot and because it was parallel with the maternal rigid control factor.

2. Regression models were also built separately by gender. However, the patterns of relations were interpretably the same.

\section{REFERENCES}

Aiken, L., \& West, S. (1991). Testing and interpreting interactions in multiple regressions. Newbury Park, CA: Sage.

Armsden, G., \& Greenberg, M. (1987). The inventory of parent and peer attachment: Individual differences and their relationship to psychological well-being in adolescence. Journal of Youth and Adolescence, 16, 427-454.

Barber,B. (1996). Parental psychological control: Revisiting a neglected construct. Child Development, 67, 3296-3319.
Barber, B., Olsen, J., \& Shagle, S. (1994). Associations between parental psychological and behavioral control and youth internalized and externalized behaviors. Child Development, 65, 1120-1136.

Barber, B.,\&Thomas, D. (1986). Dimensions of fathers' and mothers' supportive behavior: The case for physical affection. Journal of Marriage and the Family, 48, 783-794.

Barnes, H., \& Olson, D. (1985). Parent-adolescent communication in the circumplex model. Child Development, 56, 438-447.

Baumrind, D. (1991). The influence of parenting style on adolescent competence and substance abuse. Journal of Early Adolescence, 11, 56-95.

Bell, R. Q. (1968). A reinterpretation of the direction of effects in studies of socialization. Psychological Review, 75, 81-95.

Carlo, G., Raffaelli, M., Laible, D.,\& Meyer, K. (1999).Why are girls less aggressive than boys? Personality and parenting mediators of aggression. Sex Roles, 40, 711-729.

Carlo, G., Roesch, S.,\&Melby, J. (1998). The multiplicative relations of parenting and temperament to prosocial and antisocial behaviors in adolescence. Journal of Early Adolescence, 18, 266-290.

Cauce, A. (1987). School and peer competence in early adolescence: A test of domain-specific self-perceived competence. Developmental Psychology, 23, 287-291.

Collins, A., \& Russell, S. (1991). Mother-child and father-child relations in adolescence: A developmental analysis. Developmental Review, 11, 99-136.

Crouter, A., MacDermid, S., McHale, S., \& Perry-Jenkins, M. (1990). Conditions underlying parents' knowledge about children's lives in middle childhood: Between and within family comparisons. Child Development, 70, 246-259.

Crown, D., \& Marlowe, D. (1960). A new scale of social desirability independent of psychopathology. Journal of Consulting Psychology, 24, 349-354.

Darling, N.,\& Steinberg, L. (1993). Parenting style as context: An integrative model. Psychological Bulletin, 113, 487-496.

Davis, M. H. (1983). Measuring individual differences in empathy: Evidence for a multidimensional approach. Journal of Personality \& Social Psychology, 25, 70-87.

Dekovic, M., \& Janssens, M. (1992). Parents' child-rearing style and child's sociometric status. Developmental Psychology, 28, 925-932.

Dornbusch, S., Ritter, P., Leiderman, H., Roberts, D., \& Fraliegh, M. (1987). The relation of parenting style to adolescent school performance. Child Development, 58 , $1244-1257$.

Eisenberg, N., Fabes, R., Carlo, G., Troyer, D., Speer, A., Karbon, M., et al. (1992). The relations of maternal practices and characteristics to children's vicarious emotional responsiveness. Child Development, 63, 583-602.

Eisenberg, N., \& Lennon, R. (1983). Sex differences in empathy and its related capacities. Psychological Bulletin, 94, 100-131.

Eisenberg, N., \&Murphy, B. (1995). Parenting and children's moral development. In M. Borstein (Ed.), Handbook of parenting: Applied and practical parenting (Vol. 4, pp. 227-257). Hillsdale, NJ: Lawrence Erlbaum.

Feldman, S.,\& Wentzel, K. (1990). Relations among family interaction patterns, classroom self restraint, and academic achievement in preadolescent boys. Journal of Educational Psychology, 82, 813-819.

Ferreira, A., \& Thomas, D. (1984). Adolescent perception of parental behavior in the United States and Brazil. Parenting Studies, 1, 19-29.

Fischer, J., \& Crawford, D. (1992). Codependency and parenting styles. Journal of Adoles- 
cent Research, 7, 352-363.

Furstenberg, F., \& Harris, K. (1993). When and why fathers matter: Impacts of father involvement on children of adolescent mothers. In R. Lerman \& T. Ooms (Eds.), Young unwed fathers (pp. 117-138). Philadelphia: Temple University Press.

Garber, J., Robinson, N.,\& Valentiner, D. (1997). The relation between parenting and adolescent depression: Self-worth as a mediator. Journal of Adolescent Research, $12,12-23$.

Granleese, J., \& Joseph, S. (1993). Factor analysis of the Self-Perception Profile for Children. Personality and Individual Differences, 15, 343-345.

Grolnick, W., Ryan, R.,\& Deci, E. (1991). Inner resources for school achievement: Motivational mediators of children's perceptions of their parents. Journal of Educational Psychology, 83, 508-517.

Haberstroh, C., Hayslip, B., \& Essandoh, P. (1998). The relationship between stepdaughters' self-esteem and perceived parenting behavior. Journal of Divorce \& Remarriage, 29, 161-175.

Harter, S. (1982).The perceived Competence Scale for Children. Child Development, 53, 87-97.

Hein, C.,\&Lewko, J. (1994). Gender differences in factors related to parenting style: A study of high performing science students. Journal of Adolescent Research, 9 , 262-281.

Hoffman, M. (1983). Affective and cognitive processes in moral internalization. In E.T. Higgins, D. Ruble,\&W. Hartup (Eds.), Social cognition and social development:A sociocultural perspective (pp. 236-274). New York: Cambridge University Press.

Holmbeck, G., Paikoff, R., \& Brooks-Gunn, J. (1995). Parenting Adolescents. In M. Bornstein (Ed.), Handbook of parenting: Children and parenting (Vol. 1, pp. 91118). Hillsdale, NJ: Lawrence Erlbaum.

Johnson, B., Shulman, S., \& Collins, A. (1991). Systemic patterns of parenting as reported by adolescents: Developmental differences and implications for psychosocial outcomes. Journal of Adolescent Research, 6, 235-252.

Kerr, M.,\&Stattin, H. (2000). What parents know, howthey knowit, and several forms of adolescent adjustment: Further support for a reinterpretation of monitoring. Developmental Psychology, 36, 366-380.

Kochanska, G., \& Thompson, R. (1997). The emergence and development of conscience in toddlerhood and early childhood. In J. El Grusec\&L.Kuczynski (Eds.), Parenting strategies and children's internalization of values: A handbook of theoretical and research perspectives (pp. 53-77). New York: John Wiley.

Laible, D., Carlo, G., \& Raffaelli, M. (2000). The differential impact of parent and peer attachment on adolescent adjustment. Journal of Youth and Adolescence, 29, 45-59.

Lamborn, S., Dornbusch, D., Sanford, M.,\&Steinberg, L. (1996). Ethnicity and community context as a moderator of the relations between family decision making and adolescent adjustment. Child Development, 67, 283-301.

Lamborn, S., Mounts, N., Steinberg, L., \& Dornbusch, S. (1991). Patterns of competence and adjustment among adolescents from authoritative, authoritarian, indulgent, and neglectful families. Child Development, 60, 1405-1411.

Larson, R., \& Richards, M. (1994). Divergent worlds: The emotional lives of mothers, fathers, and adolescents. New York: Basic Books.

Lewis, C. (1981). The effects of parental firm control:Areinterpretation of the findings. Psychological Bulletin, 90, 547-563.
Maccoby, E., \& Martin, (1983). Socialization in the context of the family: Parent-child interaction. In E. Heatherington (Ed.), Mussen manual of child psychology (Vol. 4, 4th ed., pp. 1-102). New York: John Wiley.

Mantzieopoulos, P., \& Oh-Hwang, Y. (1998). The relationship of psychosocial maturity to parenting quality and intellectual ability for American and Korean adolescents. Contemporary Educational Psychology, 23, 195-206.

McCord, J. (1986). Instigation and insulation: How families affect antisocial aggression. In J. Block, D. Olweus,\&M.R.Yarrow(Eds.), Development of antisocial and prosocial behavior (pp. 343-357). San Diego, CA: Academic Press.

Metzler, C., Noell, J., Biglan, A., Ary, D.\&Smolkowski, K. (1994). The social context for risky sexual behavior among adolescents. Journal of Behavioral Medicine, 17, 419-438.

Papini, D., \& Roggman, L. (1992). Adolescent perceived attachment to parents in relation to competence, depression, and anxiety: A longitudinal study. Journal of Early Adolescence, 12, 420-440

Patterson, G. (1986). Performance models for antisocial boys. American Psychologist, 41, 432- 444.

Patterson, G., Bank, L.,\& Stoolmiller,M. (1990). The preadolescents contributions to disrupted family process. In R. Montemayor, G. R. Adams, \& T.P. Gullotta (Eds.), From childhood to adolescence: A transitional period? (pp. 107-133). Newbury Park, CA: Sage.

Pettit, G., Harris, A., Bates, J., \& Dodge, K. (1991). Family interaction, social cognition, and children's subsequent relations with peers in kindergarten. Journal of Social and Personal Relationships, 8, 383-402.

Putallaz, M., \& Heflin, A. (1990). Peer group behavior and social status. In S. R. Asher \& J. D. Coie (Eds.), Peer rejection in childhood (pp. 189-216). New York: Cambridge University Press.

Sagi, A. (1982). Antecedents and consequences of various degrees of paternal involvement in child rearing: The Israeli project. In M. E. Lamb (Ed.), Nontraditional families: Parenting and child development (pp. 205-232). Hillsdale, NJ: Lawrence Erlbaum.

Sagi, A., Koren, N.,\& Weinberg, M. (1987). Fathers in Israel. In M. E. Lamb (Ed.), The father's role: Cross-cultural perspectives (pp. 197-226). Hillsdale, NJ: Lawrence Erlbaum.

Sampson, R., \& Laub, J. (1994). Urban poverty and the family context of delinquency: A new look at structure and process in a classic study. Child Development, 65, 523-540.

Schoenrock, C., Bell, N., Sun, S., \& Avery, A. (1999). Family correlates of adolescent selfmonitoring and social competence. Journal of Psychology, 133, 377-393.

Shek, D. (1998). Adolescents perceptions of paternal and maternal parenting styles in a Chinese context. Journal of Psychology, 132, 527-537.

Snyder, J., \& Patterson, G. (1987). Family interaction and delinquent behavior. In H. C. Quay (Ed.), Handbook of juvenile delinquency (pp. 216-243). New York: John Wiley.

Steinberg, L. (1990). Interdependence in the family: Autonomy, conflict, and harmony in the parent-adolescent relationship. In S. S. Feldman \& G. L. Elliott (Eds.), At the threshold: The developing adolescent (pp. 255-276). Cambridge, MA: Harvard University Press.

Steinberg, L., Elmen, J., \& Mounts, N. (1989). Authoritative parenting, psychological maturity, and academic success among adolescents. Child Development, 65, 754-770. 
Steinberg, L., Lamborn, S., Dornbusch, S., \& Darling, N. (1992). Impact of parenting practices on adolescent achievement: Authoritative parenting, school involvement, and encouragement to succeed. Child Development, 63, 1266-1281.

Tabachnick, B., \& Fidell, L. (1996). Using multivariate statistics. New York: HarperCollins.

Taris, T., \& Semin, G. (1998). How mothers' parenting styles affect their children's sexual efficacy and experience. Journal of Genetic Psychology, 159, 68-81.

Worrell, L., \& Worell, J. (1974). The parent behavior form manual. Lexington: University of Kentucky Press.

Youniss, J., \& Smollar, J. (1985). Adolescent relations with mothers, fathers, and friends. Chicago: University of Chicago Press.

Zahn-Waxler, C., \& Radke-Yarrow, M. (1990). The origins of empathic concern. Motivation and Emotion, 14, 107-130.

Zakharov, A. (1982). Psychological features of children's perception of the parental role. Voprosy-Psikhologii, 1, 59-68.

Deborah J. Laible is an assistant professor in developmental psychology at Southern Methodist University. Hermain research interests are on attachment relationships, parent child communication, and socioemotional development during the preschool years and adolescence. She has published in several other distinguished journals including Child Development, Developmental Psychology, and Journal of Youth and Adolescence.

Gustavo Carlo is full professor in developmental psychology at the University of Nebraska, Lincoln. His main scholarly interest is on the individual, parenting, and cultural correlates of positive social and moral behaviors in children and adolescents. He has published in several other distinguished journals including Child Development, Developmental Psychology, Journal of Personality and Social Psychology, and Journal of Research on Adolescence and recently coedited a two-volume special issue titled "Prosocial and Moral Development in Early Adolescence" in the Journal of Early Adolescence. He is currently associate editor of the Journal of Research on Adolescence and serves on the editorial boards of Developmental Psychology and the Journal of Early Adolescence. 